\title{
TRADITION VERSUS FEMALE CIRCUMCISION: A STUDY OF FEMALE CIRCUMCISION AMONG THE ISOKO TRIBE OF DELTA STATE OF NIGERIA
}

\author{
*V.O. Awusi \\ University, Abraka, Delta State, Nigeria. \\ Correspondence: \\ Dr. V.O. Awusi \\ Department of Family Medicine \\ Faculty of Medical Sciences \\ Delta State University \\ Abraka, Delta State \\ Email: alpha.medicalcentre@yahoo.com
}

*Department of Family Medicine, Faculty of Medical Sciences, Delta State

\begin{abstract}
Introduction: Female circumcision is a culturally sanctioned tradition practiced in many Africa countries and has deleterious consequences on women's health, sexuality and fertility. Objective: To determine the extent of the practice and factors that influence decisions on female circumcision.
\end{abstract}

Methods: The first 700 female patients attending clinics at the General Hospital Oleh, a suburban community, were recruited during a 6 months period (May - October 2007).

Results: Data analyzed from 630 of them showed a high significant rate of circumcision $(66 \%)(P<0.05)$, the rate being higher among the married females. Majority of the circumcisions were done at marriage (71\%). Principal reason for circumcision was tradition (79\%). Only $16.7 \%$ of circumcised female, below age 16 years, had some form of complication immediately after the procedure.

Conclusion: Suggestions to counter the practice include enlightenment campaign aimed principally at custodians of cultural values, including women in various setting, and the introduction of sexuality education into the educational system.

Key words: female circumcision, culture, marriage.

\section{INTRODUCTION}

In every culture there exist important practices which celebrate life cycle transitions, perpetuate community cohesion, or transmit traditional values to subsequent generations. These transitions reflect norms of care and behaviour based on age, life stage, gender, and social class. While many traditions promote social cohesiveness and unity, others erode the physical and psychological health and integrity of community members, particularly girls and women. Harmful traditions exist in many different forms such as early marriage and childbearing, birth practices and female circumcision.

Female circumcision (called female genital cutting by its critics) has been practiced by many cultures at one time or the other in several parts of the world ${ }^{1,2}$. It was already in practice in Greece and Egypt in the second century B.C. ${ }^{3}$ The widespread nature of this practice makes a single origin unlikely ${ }^{4}$. Its initial practice might have been in relation to mystic rituals and initiation ceremonies for females ${ }^{4}$. It was also used by modern physicians in England and the United States, as recently as the 1940 s and 1950 s, to "treat" hysteria, lesbianism, 
masturbation, and other so called female deviances ${ }^{5}$.The practice has however become firmly established in the traditions of many peoples.

Proponents have listed several virtues resulting from female circumcision to include the promotion of chastity, genital hygiene, greater level of sexual stimulation of the husband by the narrow introitus and, it is claimed to make the vulva aesthetically more appealing ${ }^{6}$ Others advance religious reasons ${ }^{14}$

These reasons are debatable for one, sexual urge is not impaired by the removal of the clitoris and circumcised females are no less promiscuous than others ${ }^{4}$.

The numerous complications associated with infibulations, a drastic type of female circumcision where the labia majora and minora and the clitoris are totally removed with subsequent encouragement of fusion of the raw edges leaving a narrow introitus have been reported ${ }^{2,6}$. In Nigeria where the simple operation (Clitoridectomy) is more common, many of these problems are still encountered $^{7,8}$. lloabachie $^{9}$ has reported the case of an 11 year old female whose urethra was totally excised.

The problems associated with female circumcision are increasingly being highlighted in both the medical, local and international media. The inter-African Committee on Traditional Practices Affecting the Health of Women and Children (IAC) ${ }^{10}$ organized a Symposium for African Legislators in Addis Ababa in September 1997, where a plan to "ensure that by the year 2005 the practice of female genital mutilation has been completely eradicated or its incidence drastically reduced in Africa" was endorsed and adopted.

It was mainly because of this that the present study was carried out; the aim being to find out, more than 10 years after and, about 2 years after the deadline to achieve the objective of the above declaration whether female circumcision in a suburban Nigeria community is being practice, determine the size of the existing problem today by including females born within the past 5 years and identify factors that influence decisions about female circumcision. This in the author's opinion would help in reviewing and improving on the strategies aimed at the total eradication of this custom.

\section{MATERIALS AND METHODS}

Consecutive patient recruitment method was used in selecting the subjects A minimum sample size of 217 was calculated using the formula ${ }^{11}: N=Z^{2} 1-a(P)(1-P) / d^{2}$, where

$\mathrm{N}=$ minimum sample size at $95 \%$ confidence level.

$\mathrm{Z} 1-\mathrm{a}=1.96$

$\mathrm{d}=$ Precision: the difference between the true population rate and your sample rate that you can tolerate $\mathrm{P}=$ Population Prevalence

A study ${ }^{12}$ conducted in Enugu reported a prevalence of $16.5 \%$ circumcision rate among the women studied. So $17 \%$ was used as prevalence for the calculation.

Therefore, from above,

$N=(1.96)^{2}(0.17)(0.83) /(0.05)^{2}=$ 216.8.

This study was carried out at the General Hospital, Oleh, a suburban community in Isoko Local Government Area of Delta State of Nigeria, during the period May $1^{\text {st }}$ - October $31^{\text {st }} 2007$. This hospital offers general medical services to an area which includes the whole of Isoko Local Government Area and significant parts of surrounding local government areas. The patients studied were all of the Isoko tribe and mostly rural dwellers. 
Female patients of the various age groups attending the family planning, antenatal and out-patient clinics were studied. The first 700 patients were recruited, the only prerequisite being that they were Isokos. The purpose of the study was explained to them, their permission sought and a short questionnaire administered. Of interest were the patients' age, marital status, occupation and their place of origin. Others were circumcision/noncircumcision status and reason(s) for circumcision or non-circumcision. The accompanying parents (usually the mother) provided information needed in girls below the age of 16 years.
During the general examination, the vulva was inspected for evidence and type of circumcision and, for such abnormal features as labial adhesion, implantation dermoid, introital scarring or stenosis. All circumcised females were asked whether they currently had any problems attributable to the procedure. The age and period of circumcision, the circumcisionist and any immediate complication were ascertained.

Out of 700 distributed, 630 $(90 \%)$ questionnaires were correctly filled and they form the basis of this study. Statistical analysis was performed with student t-test and the level of significance selected at $\mathrm{P}<$ 0.05 .

\section{RESULTS}

Table I: FEMALE CIRCUMCISION GROUPED ACCORDING TO AGE

\begin{tabular}{|c|c|c|c|}
\hline Age (Years) & Circumcised N (\%) & Non-circumcised N (\%) & $T^{N}(\%)$ \\
\hline$<6$ & $25(24)$ & $80(76)$ & $105(17)$ \\
\hline $6-15$ & $23(21)$ & 87 (79) & $110(17$ \\
\hline $16-25$ & $68(68)$ & $32(32)$ & 100 (16) \\
\hline $26-35$ & $92(88)$ & $13(12)$ & $105(17)$ \\
\hline $36-45$ & $96(96)$ & $4(4)$ & $100(16)$ \\
\hline$>45$ & $109(99)$ & $1(1)$ & $110(17)$ \\
\hline Total & $423(66)$ & $217(34)$ & $630(100)$ \\
\hline
\end{tabular}

Table I showed the circumcision rates for the various age groups studied. The number of female circumcised $(66 \%)$ was significantly higher than the number not circumcised (34\%) $(P<0.05)$. Almost at each level and with increasing age, incidence of female circumcision increased. A sharp rise occurred between the age groups 6-15 years and $16-25$ years. Over $87 \%$ of females above 15 years of age were circumcised; while only $22.5 \%$ of females below 16 years were circumcised. Almost all the females above the age of 45 years were circumcised. 
Table II: MARITAL STATUS OF CIRCUMCISED AND NON-CIRCUMCISED FEMALE SUBJECTS

\begin{tabular}{|c|c|c|c|}
\hline Age (Years) & Circumcised N (\%) & Married (\%) & Unmarried (\%) \\
\hline$<6$ & $25(24)$ & $0(0)$ & $25(100)$ \\
\hline-15 & $23(21)$ & $6(26)$ & $17(74)$ \\
$16-25$ & $68(68)$ & $58(85)$ & $10(15)$ \\
$26-35$ & $92(88)$ & $89(97)$ & $3(3)$ \\
$36-45$ & $96(96)$ & $94(98)$ & $2(2)$ \\
\hline 45 & $109(99)$ & $109(100)$ & $0(0)$ \\
\hline Total & $413(66)$ & $356(86)$ & $57(14)$ \\
\hline Age (Years) & Non-Circumcised & Married (\%) & Unmarried (\%) \\
\hline$<6$ & $\mathbf{N}(\%)$ & & $80(100)$ \\
\hline $6-15$ & $80(76)$ & $0(0)$ & $85(98)$ \\
\hline $16-25$ & $87(79)$ & $1(2)$ & $24(75)$ \\
\hline $26-35$ & $32(32)$ & $7(25)$ & $10(77)$ \\
\hline $36-45$ & $13(13)$ & $3(23)$ & $2(50)$ \\
\hline 45 & $4(4)$ & $1(50)$ & $0(0)$ \\
\hline Total & $1(1)$ & $1(100)$ & $201(93)$ \\
\hline
\end{tabular}

Table II showed the marital status of circumcised and non-circumcised female subjects. The number of married females who were circumcised $(86 \%)$ was higher than the number not circumcised (7\%); and conversely the number of unmarried females not circumcised $(93 \%)$ was higher than the number circumcised (14\%).

For those females who were circumcised, clitoridectomy was the commonest type (98\%); 294 (71\%) had it done at marriage and $38(9 \%)$ at first pregnancy. In 34 patients the time of circumcision was not known leading one to suspect that it must have been done in infancy.

Since all the girls below 16 years of age had their mothers present at the interview, the answers to subsequent questions were regarded as being very accurate/reliable ${ }^{13,14}$, and some of these were analyzed. The elderly women in the neighbourhood performed a little more than half of the circumcisions $(54.3 \%)$. The traditional birth attendant (T.B.A), usually a female, did $25.7 \%$ of the operations and the native doctor $8.6 \%$. The staff nurse/midwife was responsible for $11.4 \%$ of the circumcisions.

Table III: IMMEDIATE COMPLICATIONS OF FEMALES CIRCUMCISED AMONG THOSE BELOW 16 YEARS OF AGE, AS GIVEN BY THEIR MOTHERS.

\begin{tabular}{l|l}
\hline Complication & N $(\%)$ \\
\hline EXCESSIVE BLEEDING & \\
\hline Circumcision by elderly & $4(8.3)$ \\
Circumcision by T.B.A. & $1(4.2)$ \\
Circumcision by a nurse & $2(2.1)$ \\
INFECTION & \\
Circumcision by elderly woman & $19(2.1)$ \\
None & $40(83.3)$ \\
Total & $\mathbf{4 8 ( 1 0 0 )}$ \\
\hline
\end{tabular}


Sixteen point seven percent $(16.7 \%)$ of females, below 16years of age, who were circumcised had some form of complication immediately after the procedure (Table III) but no persisting abnormal features were noted on examining the vulva of all the circumcised females during this study.

Table IV: REASONS FOR CIRCUMCISION AND NON-CIRCUMCISION GIVEN BY MOTHERS OF FEMALES BELOW 16 YEARS OF AGE.

\begin{tabular}{|l|c|}
\hline For circumcision & $\mathbf{N}(\%)$ \\
\hline Tradition & $7(79)$ \\
\hline Prevent promiscuity & $1(2)$ \\
\hline Father wanted it & $2(4)$ \\
\hline Pressure from other relations & $\mathbf{4 8 ( 1 0 0 )}$ \\
\hline Total & \\
\hline For non-circumcision & $142(85.0)$ \\
\hline Awaiting time of marriage & $7(4.2)$ \\
\hline No more a popular tradition & $8(4.8)$ \\
\hline Medical opinion against it & $2(1.2)$ \\
\hline May complicate labour & $2(1.2)$ \\
Father refused & $4(2.4)$ \\
Confers no benefit & $2(1.2)$ \\
\hline No particular reason & $167(100)$ \\
\hline Total
\end{tabular}

Tradition played a prominent role in the reason why the females were or were not circumcised (Table IV).

While $79 \%$ of mothers gave tradition (to prepare the girls for the task of marriage and childbearing) as reason for circumcising their daughters, $85 \%$ of mothers whose daughters were not circumcised, at the time of study, claimed will do so at daughter's marriage. Only $6 \%$ of parents did not circumcise their daughters because they were advised against it by medical personnel.

\section{DISCUSSION}

The results of this study indicate the practice of female circumcision is significantly high among the Isokos of Delta State of Nigeria.

This is in accord with studies from some part of Nigeria $-45 \%^{8}, 53 \%^{15}$, $46 \%{ }^{16}$, and some Africa communities $94 \%{ }^{17}, \quad 74 \%{ }^{18}$. The observed increasing circumcision rate with increasing age, in this study, is in accord with other studies ${ }^{8,16}$ which found that the prevalence of FGM decreased with age and increased with increasing age. The current rate of $66 \%$, found in this study, may be seen to be unacceptably high but, this may be because the study population was mainly rural where customs are largely respected and adhered to. In addition, access to health related information may be lacking in rural areas, as 
incidence of female circumcision has been reported to have dropped in areas providing access to information about its harmful consequences ${ }^{19,20}$.

The principal reason given for the practice of female circumcision in the study population was to prepare the female for the "task" of marriage and child bearing. This is the same reason given for the practice in other communities where studies ${ }^{6,16,17}$ reported that female circumcision is one of the traditional rituals done to prepare girls for womanhood. The time for circumcision varies in different cultures; while some are done in infancy $^{15}$ and at first pregnancy ${ }^{18}$, others are done at marriage ${ }^{21}$. In the study population, majority $(71 \%)$ were done at marriage while $7 \%$ at first pregnancy. Circumcision rate of $24 \%$ in females below 6 years of age seen in this study, and the reported increasing incidences of circumcision in girls below 5 years of age in other studies - $79 \%$ in Nigeria ${ }^{21}, 26 \%$ in Ghana $^{17}$ - may help to confirm the World Health Organization $(\mathrm{WHO})^{24}$ observation that the average age of girls undergoing female genital mutilation is falling, indicating that it has decreasing value as an initiation rite and more utility as a means of controlling the sexuality of women.

The high incidence of circumcision in the married female and the non-circumcision of $93 \%$ of the unmarried females, noted in this study, may indicate an association between circumcision and marriage in the community. This is made clearer by majority of the circumcisions being done at marriage. Marriage, therefore, may be an important cultural factor that motivates the females' positive attitude towards circumcision, as marriage and childbearing are important milestones for most women.

Rejecting circumcision, therefore, may carry with it a potential loss of status and acceptance, including not being eligible for marriage within the community. Men implicitly condone the practice as a way to maintain women's sexual purity, an issue of great importance to the community, as unfaithfulness on the part of the woman is believed to connote a taboo with "dire consequences" for members of the woman's nuclear family.

Some important observation which emerged during analysis of the results pertains to the involvement of trained health personnel in the practice of female circumcision and the seemingly low post-operative complications.

The presence of trained health personnel in the practice could compromise the desirable support needed from the medical community to fight this practice. The vested interests of many circumcisers play a role in the continuation and spread of the practice. Some health personnel have medicalised the custom, which reduces trauma during the procedure and infection after wards, but does not address female circumcision's long term consequences for childbearing and sexuality ${ }^{7,8}$. Since the complications of clitoridectomy have been reported to be less frequent (16.7\% in girls below 16 years of age in this study) and less severe $(0 \%$ in girls below 16 years of age in this study) than those for infibulations ${ }^{2,6}$, they are usually ignored, and clitoridectomy is falsely perceived to be safe. In addition, because communities that practice female circumcision are exposed to a high risk injuries and disease in general, fear of the health risk is not a strong deterrent given the powerful social value associated with the practice. However, it has been observed that many complicated cases, particularly in the rural areas, probably die are at home, and would therefore not be 
represented in studies like this ${ }^{22,23}$. These findings have important implications when considering strategies for the elimination of this custom.

A massive public enlightenment campaign on this ritual which confers no benefit and is attended by myriad of complications is suggested; aimed at all segments of the population to motivate and raise public awareness, emphasizing the negative consequences for women's fertility and childbearing in ways that accord with the community premium on reproduction. However, cultural beliefs and traditions are powerful and efforts to alter or eliminate harmful ones should take place carefully without alienating cultural sensibilities. Social norms concerning women's modesty and cultural notions about their sexuality must be respected.

Since the present study suggests that marriage may have a greater influence on the practice of female circumcision in Isoko land, and the reported ${ }^{13,14}$ emotional attachment to child-bearing events, including cultural events such as female circumcision, by women, programs formed within the community and funded by the government and other interested bodies should mainly be aimed at mothers, mothers/brides- tobe and the older female age group in the community since most of the circumcisionists and teachers of cultural values comes from that group. Programs should be implemented to retrain practitioners of female circumcision either to undertake different careers or to modify the practice so that it retains importance as a rite of passage but does not inflict harm upon the girl. Legislating against the practice may be counter productive $^{23}$.

A long term strategy would be to ensure universal education and introduction of sexuality education at all levels of the nation's educational system.

\section{CONCLUSION}

Female circumcision among the Isokos of Delta State of Nigeria is still significantly high. Marriage may be the major motivating factor. Public health campaigns funded by the government and other interested bodies is advocated. This should mainly be aimed at mothers, mothers/brides to be and the older female age group in the population. As a long term measure, acquisition of education by all and introduction of sexuality education into the nation's educational system will ensure a permanent eradication of this custom as envisaged by the Inter-African Committee on Traditional Practices Affecting the Health of Women and Children (IAC).

\section{ACKNOWLEDGMENT}

I wish to thank the medical officers and the nursing staff of the hospital for their assistance. Dr. V.N. Okeleke was of immense help during the period of study. I appreciate their kind help.

\section{REFERENCES}

1. United Nation Office for the Coordination of Humanitarian Affairs. When culture harms the girl - the globalization of female genital mutilation. IRIN News, 2005.

2. WHO: Female Genital Mutilation Fact Sheets. 2004.

3. Hathout HM. Some aspects of female circumcision, with case report of a rare complication. J. Obset. Gynaecol. Brit. Cwith. 1963; 70: 505-7. 
4. Hodges FM. A short history of the institutionalization of involuntary sexual mutilation in the United States. In Denniston G. and Milos MF (eds.) Sexual Mutilations: a human tragedy. New-York NY: Plenum Press, 1997, pp. 17-40.

5. Hodges FM. The antimasturbation crusade in antebellum American medicine. J. Sex Med. 2005; 2: 722-31.

6. Brady M. Female Genital Mutilation: Complications and Risk of HIV Transmission. AIDS Patient Care STDS. 1999; 13(12):709-16.

7. Okonofua FE, Oronsanya F and Larsen $U$. The association between female genital cutting and correlates of sexual and gynaecological morbidity in Edo State, Nigeria. BJOG 2002; 109:1089-96.

8. Larsen U, Okonofua F. Female circumcision and obstetric complications. Int. J. Gynaeco. Obstet.2002; 77 (2): 225-326.

9. Iloabachie GC. Urinary incontinence; circumcision - A case report with details of urethral reconstruction from vaginal tissues. Orient. J. Med. 1990; 2: 81-84.

10. Inter-African Committee on Traditional Practice Affecting the Health of Women and Children (IAC). African Legislators call for end of Female Genital Mutilation. Passages 1998; 15(4): 2-5.
11. Oyejide CO. Health Research Methods for Developing Country Scientists. Codat Publications, Ibadan, Nigeria. 1992; pp. 59-63.

12. Meniru GI. Female circumcision among the Igbos of Nigeria: Trends. Nig. J. Med. 1991; 1(2): 55-60.

13. Chidambaram VC, Cleland JG, Goldman N, Rutstein S. An assessment of the quality of WFS demographic data. Source: In: The analysis of maternity histories, edited by Allan G. Hill and William Brass Liege, Belgium, Editions Derouaux-Ordina, 1992: 183215.

14. Xasan DF. Final resolutions In: Female circumcision: stategies to bring about change. Proceedings of the International Seminar on Female circumcision, 13 - 16 June 1988, Mogadisho, Somalia, [compiled by] Associazione Italiana Donne per lo Sviluppo [and] Somali Women's Democratic Organisation. Rome, Italy, Associazione Italiana Donne per lo Sviluppo, 1989: 121-5.

15. Adeokun LA, Oronsaye $F$, Gbogboade AO, Aliyu N, Adekunle $W$ et al . Trends in Female Circumcision between 1933 and 2003 in Osun and Ogun States, Nigeria (A Cohort Analysis). Afr. J. Reproduc, HIth. 2006; 10(2): 48-56.

16. Snow RC, Slamger TE, Okonofua FE, Oronsaye F, Wacker J. Female genital cutting in southern urban and 
peri-urban Nigeria: Selfreported validity, social determinants and secular trend decline. Tropical Medicine and International Health 2002; 7(1): 91-100.

17. Mbacke $\mathrm{C}$, Adongo $\mathrm{P}$, Akweongo $\mathrm{P}$, Binka FN. Prevalence and correlates of female genital mutilation in the Kassena-Nankana District of Northern Ghana. Afr. J. Reproduct. HIth. 1998; 2(2): 1324.

18. Jackson $E F$, Akweongo $P$, Hodgson A, Asuru R, Phillips JF. Women's Denial of Having Experienced Female Genital Cutting in Northern Ghana: Explanatory Factors and Consequences for Analysis of Survey Data. Population Council, 2003.

19. Nkwo PE, Onah HE. Decrease in female genital mutilation among Nigerian Igbo girls. Int. J. Gynaecol. Obstets. 2001; 75(3): 321-2.

20. Sbanda A, Zuberi T. In: Third African Population Conference, Durban, South Africa, 6 - 10
December 1999. The African Population in the 21st Century. Troisieme Conference Africane sur la Population, La Population Africane au 21e slede. Volume 1, [compiled by] Union for African Population Studies. Dakar, Senegal, Union for African Population Studies 1999: 79-108.

21. Nigeria Demographic and Health Survey. National Population Commission, Federal Republic of Nigeria. 2003.

22. Anonymous. Female genital mutilation: a traditional rite that affects women's health. Contraception Report 1995: 6 (1): 12-13.

23. Raufu A. Nigeria recommends jail terms to eradicate female genital mutilation. BMJ 2002; 324(7345): 1056.

24. World Health Organization. Female Genital Mutilation: A Joint WHO/UNICEF/UNFPA statement. Passages January 1998; 15(4): 1-8. 